\title{
Makna Lokalitas Wajah Bangunan Kolonial di Pusat Kota Krian- Sidoarjo
}

\author{
Eko Febrianto ${ }^{1}$, Lisa Dwi Wulandari ${ }^{2}$, Antariksa ${ }^{3}$ \\ 1 Program Magister Arsitektur Lingkungan Binaan Universitas Brawijaya Malang \\ ${ }^{283}$ Fakultas Teknik Universitas Brawijaya Malang \\ 1best84.febrian@gmail.com, ${ }^{2}$ lisaromansya@yahoo.co.uk, ${ }^{3} \mathrm{mr}$. antariksa@gmail.com
}

\begin{abstract}
ABSTRAK
Arsitektur pada dasarnya merupakan wujud kreativitas manusia dalam kehidupan baik sebagai makhluk individu maupun makhluk sosial yang berbudaya sekaligus bentuk adaptasi terhadap kondisi alam. Kota Krian merupakan kota tua dan mengalami perkembangan pesat pada jaman kolonial Belanda. Gaya arsitektur kolonial kemudian berkembang dan menjadi tren bagi masyarakat lokal yang didominasi oleh suku jawa.Uniknya bangunan-bangunan gayakolonial tersebut dibangun dan dimiliki oleh warga lokal. Wajah bangunan sebagai ekspresi pemiliki rumah menjadi komponen utama dalam membentuk citra kawasan, tetapi saat ini akibat perkembangan kota banyak terjadi perubahan wajah bangunan dan fungsi bangunan yang mengdegradasi hal tersebut. Tujuan studi adalah untuk mengetahui makna bentuk elemen wajah bangunan bergaya kolonial di Kota Krian. Metode penelitian menggunakan kualitatif deskriptif dengan pengamatan pada elemen-elemen wajah bangunan sehingga dapat dianalisis tipologi yang bermuara pada makna wajah bangunan. Hasil penelitian menjelaskan makna dari setiap bentuk elemen wajah bangunan berdasarkan orientasi, atap, pintu, jendela, kolom bangunan, lantai bangunan, dan ornamen bangunan.
\end{abstract}

Kata Kunci :wajah bangunan, makna, gaya kolonial

\begin{abstract}
Architecture is basically a form of human creativity, both as individual and social creature, as the adaptation with the environment. Krian City is the old town and has experiencing with a rapid development in the colonial era. Afterwards, colonial architectural styles evolved and became a trend for local communities that dominated by Javanese. Colonial style buildings were built and owned by the local residents(Javanese). Building facade as an expression of the owner has became a major component in shaping the image of the city, however, presently, due to the development of Krian City;it make many changes in building façade and the function of the buildings. The aim of this study is to find out the meaning of the elements from building façade in the colonial style buildings in Krian City. This research uses descriptive qualitative methodology, by doing observations on the building facade elements, then analyzed byperforms building typology of building facade. The results of this study has described the form of building façade elements meaning based on the orientation of the building, roof, doors, windows, column, floor, and ornamentation.
\end{abstract}

Keywords: building facade, meaning, colonial style 


\section{Pendahuluan}

Kota pada dasarnya merupakan langgam dari artefak formal dan produk dari berbagai individu warga kota. Keberadaan kota jugatidak terlepas dari proses perkembangannya di masa lalu, sekarang dan masa yang akan datang(Rossi, 1982). Keberadaan suatu kota tentu tidak akan terlepas dari perkembangan bangunanbangunan yang berfungsi untuk mengakomodasi aktivitas dan kebutuhan warga kota sehingga arsitektur dari bangunan-bangunan kota akan terus mengikuti perkembangan jaman atau tren pada masanya.

Kota Krian telah melalui berbagai masa dalam perkembangannya, dari masa kerajaan, masa kolonial sampai pasca kemerdekaan. Hal ini kemudian menjadikan kota Krian begitu kaya akan bangunan-bangunan kuno dan bersejarah terutama bangunanbangunan bergaya kolonial Belanda.Keberadaan bangunanbangunan bergaya kolonial tersebut sampai saat ini sebagian masih berdiri kokoh dan masih dipertahankan oleh warga karena memiliki keunikan desain dan kualitasnya yang baik.

Perkembangan bangunan bergaya kolonial di Kota Krian terjadi semenjak adanya kebijakan pemerintah Kolonial terkait ekonomi yang bertumpu pada basis pertanian terutama tanaman tebu yang menjadi komoditas utama untuk industri gula. Hadirnya pabrik Gula Krian dan stasiun kereta api yang keduanya menjadi simpul industri gula di kawasan Sidoarjo dan menjadi simpul transportasi untuk angkutan penumpang dan barang menjadikan kota Krian menjadi salah satu simpul ekonomi di kawasan Sidoarjo dan Surabaya.

Ekonomi yang semakin baik dan masuknya budaya luar terutama arsitektur kolonial yang saat itu menjadi tren membuat masyarakat jawamemilih membangun rumah dengangaya bangunan kolonial Belanda sebagai model rumah mereka.Tentu hal ini menjadi sesuatu hal yang menarik sebab bangunan-bangunan bergaya kolonial yang ada di Kota Krian dibangun dan dimiliki oleh masyarakat jawa. Dengan demikian, tentu ada bagian-bagian elemen pada bangunan, terutama wajah bangunan yang merupakan bentuk kepercayaan masyarakat jawa akan adanya hubungan yang harmonis antara manusia dengan Tuhan, manusia dengan sosial dan manusia dengan alam (Noeradya, 2005).

Rumah bagi masyarakat Jawa menunjukkan simbol status bagi penghuninya dan juga mengandung makna tentang kehidupan penghuni. Rumah juga menjadi sarana pemilik untuk menunjukkan siapa sebenarnya dirinya sehingga dapat dimengerti dan dinikmati orang lain. Rumah menyangkut dunia batin yang tidak pernah lepas dari kehidupan masyarakat Jawa (Ismunandar,1986).

Dalam masyarakat jawa, rumah menjadi bagian penting dalam hidupnya karena adanya keyakinan akan budaya/kepercayaan yang turun temurun yang terkait kehidupan dimasa yang akan datang. Oleh sebab itu dalam membangun rumah tentu akan banyak pertimbangan akan bentuk elemen yang akan digunakan agar memiliki pesan / makna yang baik.

Wajah bangunansebagaielemen terpenting yang mampu menyuarakan fungsi dan makna sebuah bangunan.Wajah bangunanadalah representasi atau ekspresi dari berbagai aspek yang muncul dan dapat diamati secara visualyang dapat menyampaikan keadaan budaya atau tren saat bangunan tersebut dibangun. Wajah bangunandapat mengungkap kriteria penataan dan tatanan sekaligus memberikan kreativitas dalam ornamentasi dan dekorasi yang kemudian dapat ditipologikan berdasarkaan kriteria tertentu untuk kemudian digunakan untuk berbagai kepentingan (Krier, 1988)

Menurut Lippsmeier (1980), elemen wajah bangunan yang sekaligus 
merupakan komponen-komponen yang mempengaruhi fasade bangunan dan dapat dijadikan dasar dalam menganalisis adalah bagian atap, dinding, dan lantai. Selanjutnya Krier (1988) mendetailkan elemen-elemen dari wajah bangunan yang dapat dianalisis menjadi elemen atap, pintu, jendela, kolom, dinding dan lantai.

Dalam penelaahan wajah bangunan kolonial, ada hal lain yang harus diperhatikan adalah keberadaan ornamen hias pada setiap elemen bangunan yang biasanya dapat berupa ukiran, motif bentuk dari elemen maupun penambahan bentuk tertentu. Motif-motif tersebut pada bangunan bergaya kolonial Belanda dapat ditemukan misalnya pada Gable/gevel, Tower/Menara,

Ballustrade, Bouvenlicht, Hiasan puncak atap maupun bagian lainnya (Krier, 2001). Dengan demikian, studi terkait makna lokalitas bentuk elemen wajah bangunan kolonial di Kota Krian menjadi studi yang menarik karena akan menguak keberlanjutan simbolisasi kepercayaan masyarakat lokal pada bangunan bergaya kolonial yang saat ini menjadi langka sebab saat ini banyak bangunan yang dibangun tanpa "makna".
Analisis makna dalam arsitektur dapat dilakukan dengan menelusuri teori-teori kepercayaan atau tradisi budaya jawa dalam arsitektur dan dikuatkan dengan hasil temuan informasi di lapangan. Makna akan mengacu pada sejauh mana masyarakat yang membangun dan memiliki rumah menerapkan kepercayaan atau tradisi budaya jawa walaupun bukan pada bangunan jawa sehingga sebenarnya pada era modernpun kepercayaan dan tradisi terkait arsitektur jawa masih dapat diterapkan.

Dalam falsafah hidup orang jawa, adakepercayaan bahwa dalam hidup itu harus menerapkan konsep hidup yang seimbangyaitu adanya harmonisasi hubungan manusia dengan Tuhan, manusia dengan alam serta manusia dengan sesama manusia (Fauzy, 2011).

Perwujudan falsafah hidup tersebut ternyata juga diwujudkan dalam arsitektur bangunan tempat tinggal secara turun temurun.Tempat tinggal atau rumah bagi masyarakat jawa kaya akan makna yang mengekspresikan diri dan nenek moyangnya. Oleh sebab itu, rumah-rumah orang jawa umumnya memiliki bentuk dan simbolisasi tertentu yang dapat diwujudkan dalam arsitektur.

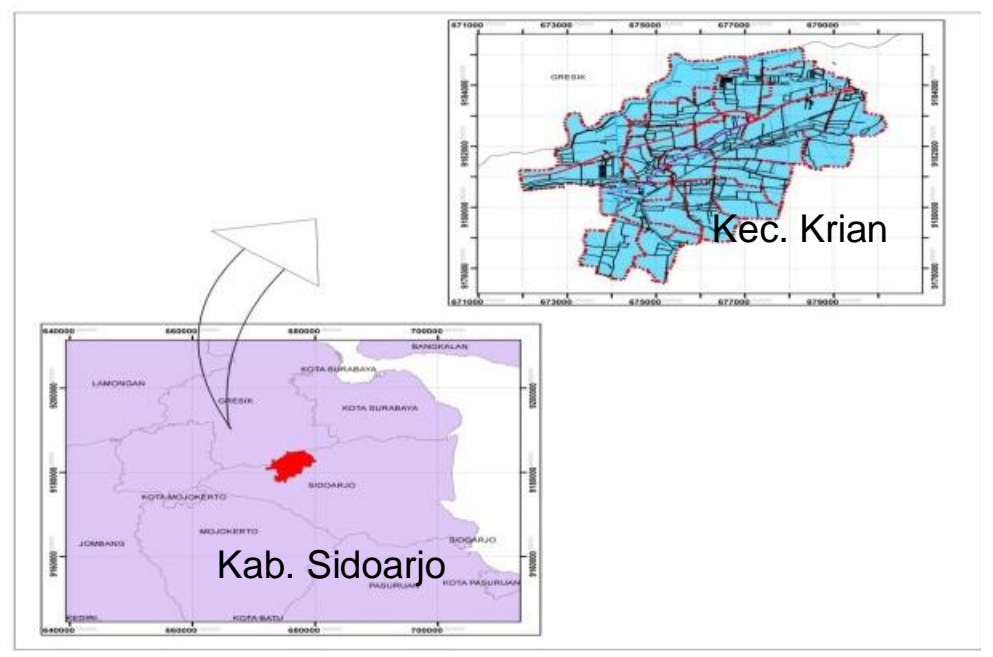

Gambar 1: Posisi Kec. Krian dalam konstelasi Kabupaten Sidoarjo Sumber: Diolah dari RDTR Kec. Krian 


\section{Metodologi}

Penelitian ini menggunakan metode kualitatif deskriptif yang penerapannya akan mentipologikan bentuk elemenelemen wajah bangunan kolonial untuk kemudian dianalisis maknanya berdasarkan teori dan hasil temuan dilapangan dari sudut pandang kepercayaan masyarakat jawa sehingga didapat makna lokalitaspada wajah bangunan kolonial di Kota Krian.

Objek penelitian adalah bangunanbangunan bergaya kolonial yang dimiliki dan dibangun oleh masyarakat lokal, memiliki wajah bangunan yang masih asli ataupun jika telah mengalami perubahan maka perubahan itu tidak merubah struktur. Amatan fokus pada elemen-elemen wajah bangunan kolonial antara lain atap, dinding, pintu dan jendela, kolom depan dan lantai bangunan serta tentunya ornamen hias pada elemenelemen tersebut. Analisis dilakukan dengan mengkaitkan dengan teori-teori agar data-data temuan lapangan dapat dideskripsikan secara baik dan jelas.

Studi ini tepatnya berlokasi di Dusun Magersari, Dusun Krajan dan Dusun Jagalan di Kelurahan Krian, Kecamatan Krian, Kabupaten Sidoarjo. Pemilihan ketiga dusun tersebut dikarenakan merupakan pusat kota dan lokasi paling banyak sebaran bangunan-bangunan bergaya kolonial yang masih asli wajah bangunannya. Selain itu dinamika arsitektur di lokasi tersebut sangat majemuk dari mulai kolonial, jawa dan cina sebab kampung kota Krian dihuni oleh warga multi etnis.

Jumlah bangunan yang menjadi objek penelitian sebanyak 16 buah yang tersebar di Dusun Magersari, Dusun Krajan dan Dusun Jagalan.Bangunan-bangunan tersebut rata-rata dibangun sebelum abad 19 dan awal abad 19 sampai era awal kemerdekaaan sehingga umur bangunan kesemuanya diatas 50 tahun.

Penelitian dilakukan dengan survei primer dan sekunder serta wawancara denganpenghuni serta informan kunci untuk memperoleh informasi yang lebih komprehensif terkait kepercayaan dan tradisi dalam arsitektur jawa di Kota Krian.Data-data tersebut direkam dengan menggunakan sketsa, foto, dan rekaman wawancara. Proses analisis dilakukan dengan melakukan analisis tipologi untuk men-tipe-kan bentuk elemen bangunan dan tahap selanjutnya baru dilakukan analisis makna dari sudut pandang masyarakat jawa.

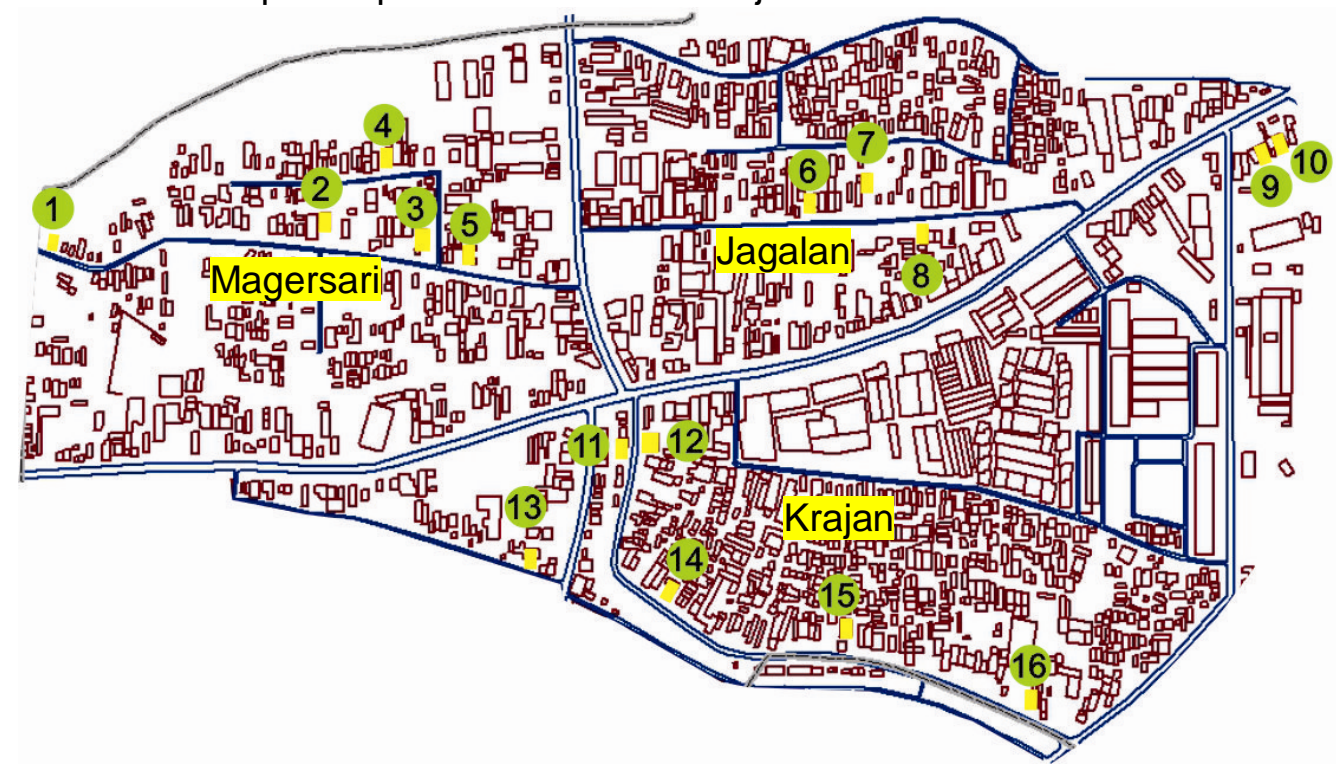

Gambar 2: Sebaran Objek Penelitian Sumber: Dokumentasi Pribadi, 2014 


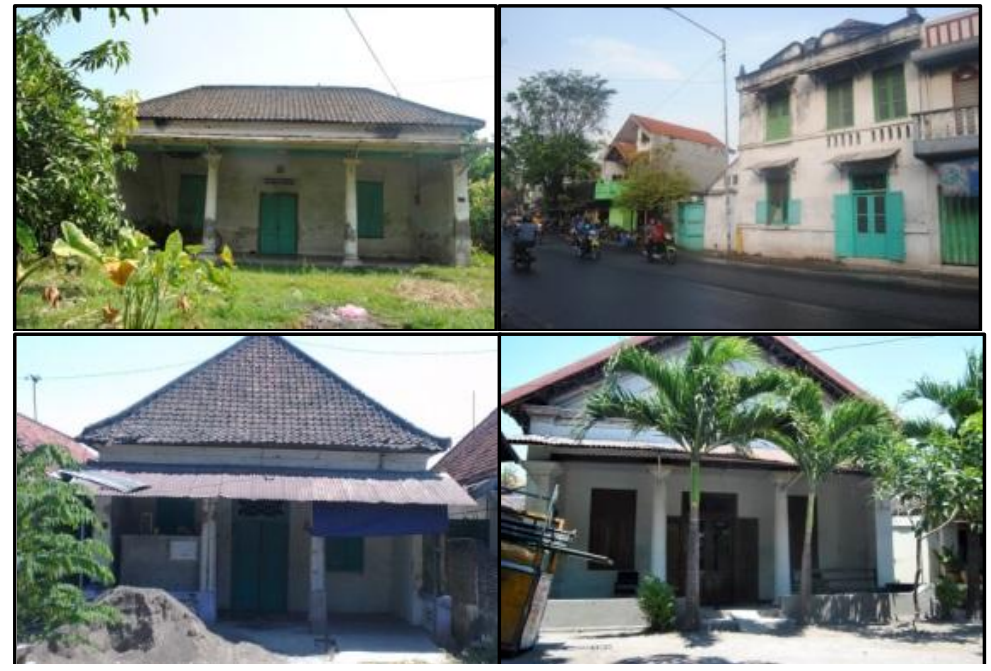

Gambar 3: Gambaran Bangunan Kolonial Sumber: Dokumentasi Pribadi, 2014

\section{Hasil dan Pembahasan}

\subsection{Sejarah Singkat Kota Krian}

Kawasan Krian pada jaman dahulu diyakini sebagai bagian dari Kerajaan Majapahit yang dibuktikan dengan ditemukannya berbagai situs atau peninggalan sejarah yang terkait dengan kekuasaan Majapahit yang kemudian di kenal dengan Kadipaten Terung.Hal ini mengindikasikan bahwa peradaban di kawasan Krian telah maju dari jaman dahulu kala termasuk didalamnya perkembangan arsitektur.

Pada tahun 1800-an, adanya kebijakan pemerintah kolonial yang terbuka terhadap kegiatan ekonomi membuat perekonomian regional dalam industri gula di Krian tumbuh.Aglomerasi ekonomi di kawasan Krian berkembang begitu pesat sehingga taraf hidup masyarakat lokal banyak yang semakin baik. Proses hubungan dagang dan kemudahan mobilitas warga menjadikan Krian menjadi salah satu basis perkembangan budaya kolonial. Bangunan-bangunan kolonial mejadi tren dikalangan warga termasukcara hidup dan pergaulan terutama bagi warga yang berada/kaya.Dengan demikian tidaklah mengherankan berkembang bangunan-bangunan bergaya kolonial Belanda di Kawasan
Krian yang dibangun dan dimiliki oleh warga lokal (jawa).

\subsection{Makna Bentuk Elemen Wajah Bangunan}

Sebelum melakukan analisis terkait makna bentuk elemen wajah bangunan maka dilakukan analisis tipologi bangunan (Tabel 1) agar didapat tipe dari bentuk elemen-elemen wajah bangunan.Analisis tipologi dapat dilakukan dengan mengacu pada elemen-elemen wajah bangunan sebagai variabel untuk men-tipe-kan. Dalam penelitian ini karakter elemen wajah bangunan yang ditipologikan dibagi dalam beberapa elemen yaitu :

1. Atap ;

2. Pintu dan Jendela ;

3. Kolom ; dan

4. Lantai ;

5. Dilengkapi dengan orientasi wajah bangunan dan ornamen hias.

Kesemua elemen tersebut akan dianalisis satu persatu dan didapat hasil sebagai berikut :

\section{A) Atap}

Atap merupakan elemen yang sangat mudah untuk diamati dan banyak dijadikan sebagai prioritas kualitas dan bentuk karena menaungi bagian bangunan lainnya. Atap adalah elemen wajah bangunan yang dapat 
mempengaruhi bentuk,keindahan suatu bangunan dan dapat membuat view menjadi unik / berbeda dengan bangunan lainnya (Krier, 2001).

Dari hasil analisis tipologi, maka bentuk atap bangunan kolonial di pusat kota Krian dibagi dalam 2 tipe, yaitu :

1. Atap perisai, dengan beberapa modifikasi seperti atap perisai ganda.Atap tipe perisai tersebar pada rumah no : $1,3,4,5,6,7,8$, 11, 13, 14, dan 16.

2. Atap pelana, atap tipe pelana tersebar pada rumah no: 2, 9, 10, 12 dan 15.

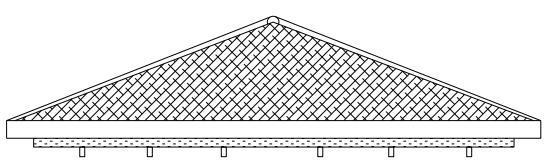

(a)

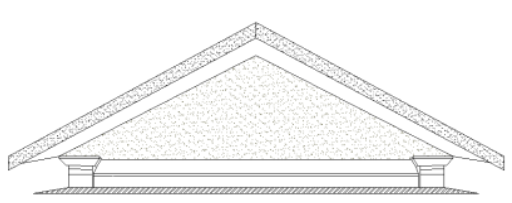

(b)

Gambar 4: Gambaran Tipe atap Perisai (a) dan tipe atap pelana (b). Sumber:

Dokumentasi Pribadi, 2014

Material yang digunakan untuk atap pada bangunan bergaya kolonial di Pusat Kota Krian adalah sama yaitu penggunaan genteng yang terbuat dari tanah liat berkualitas baik. Atap-atap bangunan tersebut umumnya memiliki sudut kemiringan yang cukup tajam yaitu antara $40^{\circ}-50^{\circ}$ yang berfungsi agar aliran air pada saat hujan dapat mengalir dengan baik ke bawah dan disempurnakan dengan penggunaan teritisan sebagai bentuk adaptasi lingkungan tropis pada bangunan kolonial.

Pada atap perisai dan pelana, bagi masyarakat jawa dimaknai sebagai perwujudan simbolisasi gunung yang menunjukkan hubungan yang harmonis antara manusia dan Tuhannya.(Fauzy, 2011). Di Jawa Timur, keberadaan gunung terutama gunung berapi sudah menjadi bagian dalam kehidupan kesehariannya dan dianggap memiliki nilai sakral seperti di sekitar Kota Krian yang banyak terdapat gunung berapi seperti Gunung ljen, Gunung Arjuna dan beberapa gunung lainnya. Selain makna tersebut, penggunaan atap perisai digunakan untuk menunjukkan bahwa pemiliknya adalah keturunan bangsawan atau pejabat/pegawai, sedangkan atap kampung digunakan untuk menunjukkan bahwa pemilik rumah adalah rakyat biasa yang sukses. (Frick, 1997)

Penerapan bentuk atap ini sampai saat ini masih dipertahankan, walaupun dengan gaya bangunan yang modern terutama pada kampung-kampung Kota Krian.

\section{B) Pintu}

Pintu merupakan elemen yang tidak terlepaskan dalam suatu bangunan, setiap bangunan memiliki pintu.Dari sisi bentuk, hasil analisis tipologi menunjukkan tipe pintu bangunan kolonial di Kota Krian berupa :

1. Tipe Kupu tarung, baik dengan 2 daun pintu maupun 4 daun pintu yang dapat dibuka $180^{\circ}$ kearah luar dan dalam. Sebaran pintu Tipe kupu tarung. Sebaran tipe pintu kupu tarung terdapat pada rumah no. $1,2,3,4,5,6,7,8,9,10,11$, 13, 14, 15 dan 16 .

2. Tipe pintu geser, dengan beberapa daun pintu yang dapat dibuka dengan menggeser daun pintu. Sebaran tipe ini hanya pada rumah no. 12.

Dari sisi material yang digunakan, penggunaan kayu jati sangat dominan, karena bagi masyarakat jawa, kayu jati telah menjadi tradisi sebagai material utama pada pintu karena kuat dan tahan

lama, baik dibentuk panil maupun kisikisi/jalusi. Selain itu, pada beberapa rumah sudah ada yang menggunakan kaca.

Bentuk pintu kupu tarung yang berada di tengah bangunan, dimaknai oleh masyarakat jawa di Kota Krian sebagai simbolisasi keluarga / 
penghuni yang ramah sebagai wujud hubungan manusia - sosial (kehidupan sesama manusia). Dalam masyarakat jawa, ada kepercayaan bahwa hidup itu harus seimbang, tidak hanya harmonisasi hubungan manusia dengan Tuhan dan lingkungan alam, tetapi juga dengan sesama manusia (Dewi, 2003).Dengan demikian diyakini oleh masyarakat Jawa di Kota Krian hidupakan bahagia dan rezeki lancar karena adanya sifat saling memberi, tahu tata krama, tenggang rasa dan saling menghargai dalam kehidupan bermasyarakat.Pintu bentuk geser bagi masyarakat jawa Krian tidak memiliki pesan/makna tertentu, tetapi diterapkan karena fungsi.Pintu tipe geser diterapkan dengan mengadopsi bangunan-bangunan komersial/toko miliki tionghoa agar lebih mudah dalam memajang barang dagangannya.

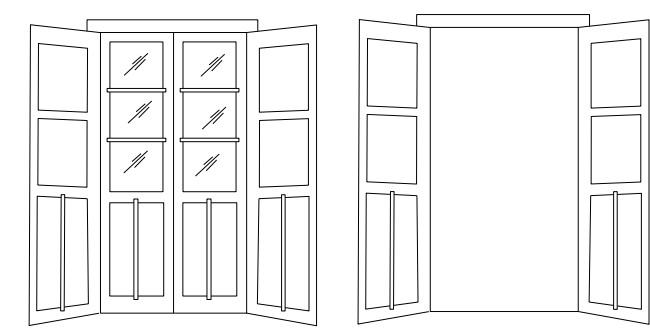

Gambar 5:Tipe Pintu Kupu Tarung dengan 4 dan 2 daun pintu. Sumber: Dokumentasi Pribadi, 2014

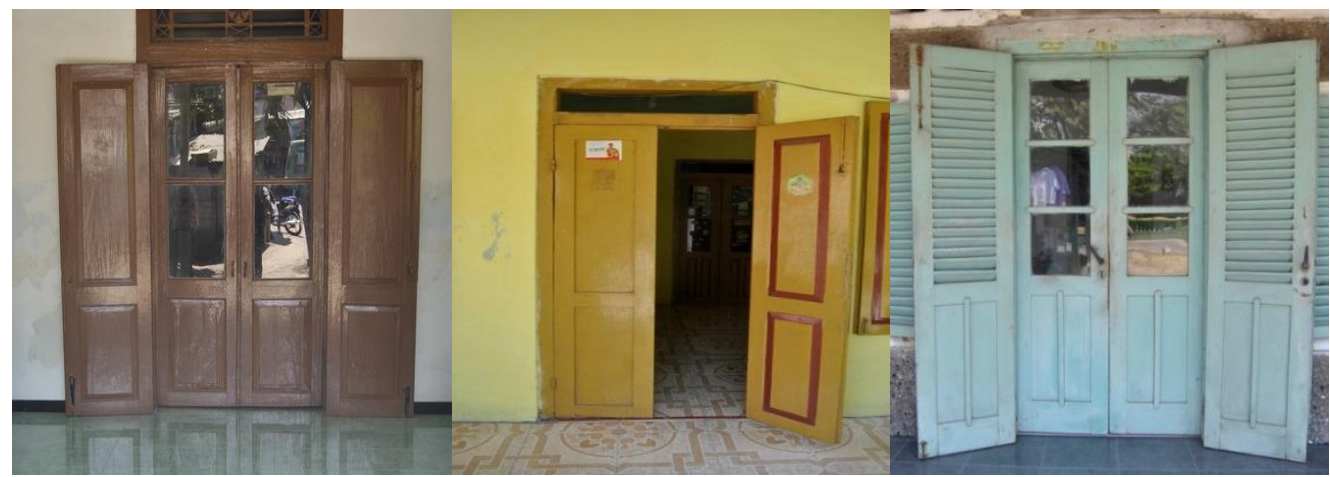

Gambar 6: Gambaran macam-macam pintu tipe kupu tarung Sumber: Dokumentasi Pribadi, 2014

\section{C) Jendela}

Jendela merupakan bukaan pada sebuah dinding di sebuah bangunan yang memasukkan cahaya dan udara ke dalam ruang dalam (interior).Jendela berkembang seiring zaman, tetapi tujuan utamanya untuk memasukkan sinar matahari menjadi aturan yang utama.Bukaan jendela merupakan elemen yang dapat memodifikasi iklim luar ke dalam interior (Philips dan Gardner, 2004).

Dari hasil analisa tipologi, berdasarkan bentuk maka tipologi pintu bangunan bergaya kolonial di Kota Krian berupa :

1. Kupu Tarung, dengan 2 daun jendela maupun 4 daun jendela yang sebarannya pada rumah no. $2,3,4,5,6,7,9,10,11,12,13,14$, 15 dan 16.

2. Ayun tunggal rumah,yang menggunakan satu daun jendela yang dapat dibuka keluar $180^{\circ}$. Tipe ini terdapat pada rumah no. 1 dan 8 Bentuk kupu tarung bagi masyarakat jawa di Kota Krian merupakan simbolisasi rohani dan badani yang menyatu atau memiliki satu fungsi agar hidup penuh rezeki dan kesenangan. Dalam falsafah hidup orang jawa, ketergantungan hidup tidak hanya pada alam, tetapi juga pada hubungan dengan sesama manusia yang harmonis.(Dewi, 2003), 
sedangkan bentuk ayun tunggal tidak memiliki makna tertentu.

Ditinjau dari sisi fungsi jendela, maka peran jendela pada masyarakat jawa sebenarnya lebih dimaknai sebagai hubungan mikrokosmos (ruang dalam) ketimbang sebagai ventilasi udara (Satwiko, 2013), Semakin gelap ruang dalam maka makin sakral pula ruangan tersebut, sehingga tidak mengherankan jika ukuran jendela pada bangunan bergaya kolonial di Kota Krian lebih kecil dibandingkan dengan jendela pada bangunan kolonial pada umumnya.
Secara umum material yang digunakan pada jendela adalah dominan menggunakan kayu jati karena merupakan jenis kayu yang kuat, mahal dan memiliki nilai mitos tersendiri bagi warga jawa di kota Krian. Jenis kayu jati yang digunakan menggunakan jenis kayu yang sudah berumur puluhan tahun sehingga dari sisi kekuatan dan kualitas tidak diragukan lagi.Untuk material kaca, digunakan selain untuk mempercantik tampilan tetapi juga memudahkan arah pandangan ke luar karena transparan.

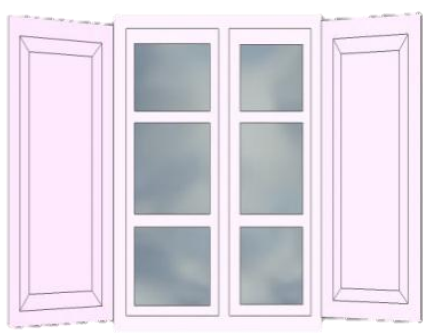

(a) (b)

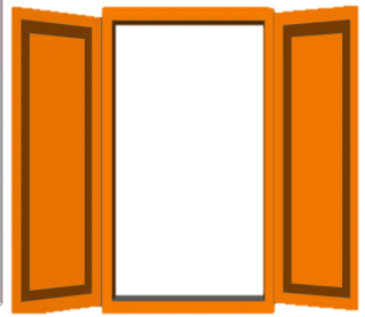

(c)

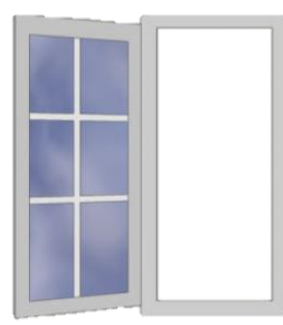

Gambar 7: Tipe jendela kupu tarung Sumber: Dokumentasi Pribadi, 2014

\section{D) Kolom}

Kolom atau tiang adalah bagian bangunan yang berfungsi menyangga atap dan diletakkan vertikal.Kolom atau tiang sangat penting dalam menjaga struktur bangunan agar dapat bertahan dari goncangan, cuaca dan tekanan, oleh sebab itu biasanya material dari Kolom atau tiang menggunakan material yang kuat dan tahan lama.

Kolom atau tiang pada wajah bangunan bergaya kolonial di kota Krian ada yang menggunakan atau tidak. Yang menggunakan kolom atau tiang adalah bangunan yang memiliki teras sedang yang tidak memiliki tiang atau kolom adalah bangunan yang tidak memiliki teras.

Dari hasil analisa, berdasarkan bentuk maka tipe kolom pada bangunan kolonial di Kota Krian dibagi 3 yaitu :
1) Kolom bulat, terdapat pada rumah no. 3, 7, 9 dan 10 .

2) Kolom persegi empat, terdapat pada rumah no. $1,2,3,4,5,6,7,9$, 10, 14 dan 15;

3) Kolom segi delapan. terdapat pada rumah no. 16.

Jumlah tiang/kolom pada teras bangunan ada yang berjumlah 4 dan ada pula yang hanya 3. Dan untuk bentuk kolom/tiang tersebut ada yang menggunakan persegi empat semua, ada yang menggunakan kombinasi persegi empat dan bulat serta kombinasi persegi empat dan persegi delapan., sedangkan material kolom/tiang yang digunakan adalah pasangan bata merah yang diplester semen dan tidak ada yang menggunakan kayu 


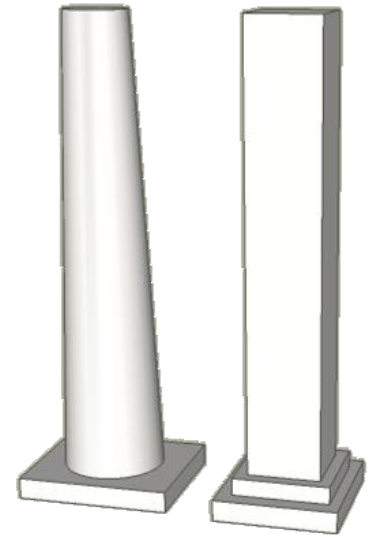

(a)

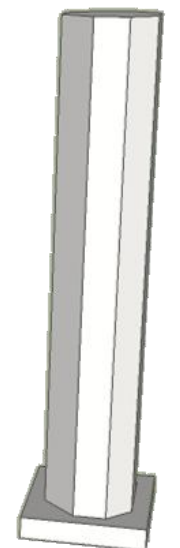

(c)
Gambar 8: Tipe (a) Kolom bulat, (b) Kolomsegi empat dan (c) Kolom segi delapan. Sumber: Dokumentasi Pribadi, 2014

Simbolisasi bentuk lingkaran merupakan bentuk yang dipergunakan untuk menggambarkan kesempurnaan hidup.Bentuk tersebut melambangkan kesempurnaan Tuhan, sedangkan bentuk kolom persegi empat dan delapan melambangkan ketidaksempurnaaan (Dakung, 1981).Dari simbolisasi tersebut nampak masyarakat jawa sangat memahami hubungan manusia dengan Tuhan yaitu kesempurnaan hanya milik Tuhan dan ketidaksempurnaan adalah milik manusia.Falsafah hidup yang sampai saat ini masih terapkan dalam kehidupan masyarakat jawa.

\section{E) Lantai}

Lantai adalah tempat berpijak di dalam bangunan atau tempat tinggal.Perkembangan peradaban manusia menjadikan lantai sangat dibutuhkan baik segi fungsional maupun segi keindahan (estetika).

Pada bangunan bergaya kolonial yang ada di kota Krian, bentuk lantai dapat ditipologikan kedalam 1 tipe saja yaitu mengalami peninggian (ditinggikan). Dari sisi ketinggian lantai, maka lantai pada bangunan bergaya kolonial di kota Krian, semuanya mengalami peninggian antara 2 sampai 7 anak tangga. Hal ini dilakukan karena kawasan Krian dikelilingi oleh sungaisungai sehingga meninggikan lantai adalah sebagai bentuk adaptasi terhadap kondisi lingkungan. Bentuk adaptasi ini merupakan respon kepercayaan jawa akan bagaimana menjalin hubungan yang harmonis antara manusia dan alam (Fauzy, 2011)

Selain itu, peninggian ini sebagai simbolisasi bahwa rumah adalah tempat yang memiliki nilai sakral.Bagi masyarakat jawa semakin tinggi bangunan maka semakin tinggi nilai sakralnya.Dari sisi material yang digunakan, maka lantai ada yang menggunakan :

1. Perkerasan semen polos / plester. Jenis material ini tergolong paling sederhana dan paling murah, karena diperlakukan seperti saat memplester dinding dan diaci hingga halus. Material ini adalah material awal pada semua lantai bangunan bergaya kolonial di Kota Krian.

2. Keramik.

Jenis material ini sangat umum digunakan pada bangunan, dan pada beberapa bangunan bergaya kolonial di kota Krian ada yang telah diganti perkerasan semen dengan keramik karena lebih indah dan mudah diaplikasikan.

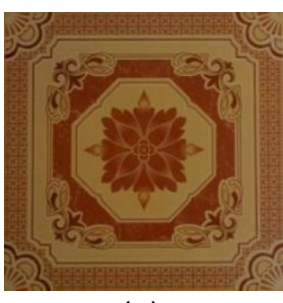

(a)

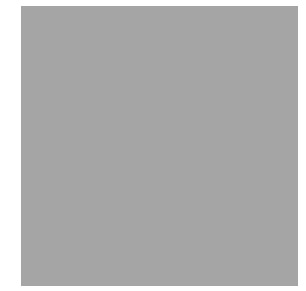

(b)
Gambar 9: Tipe (a) Tipe lantai keramik, (b) Tipe lantai plester. Sumber: Dokumentasi Pribadi, 2014 
Tabel I: Matriks Tipologi Wajah Bangunan 16 Bangunan Objek Penelitian

\begin{tabular}{|c|c|c|c|c|c|c|c|}
\hline NO & $\begin{array}{l}\text { NOMOR } \\
\text { RUMAH }\end{array}$ & ORIENTASI & TIPE ATAP & $\begin{array}{c}\text { TIPE } \\
\text { JENDELA }\end{array}$ & TIPE PINTU & $\begin{array}{c}\text { TIPE } \\
\text { KOLOM }\end{array}$ & $\begin{array}{c}\text { TIPE } \\
\text { LANTAI }\end{array}$ \\
\hline 1. & Rumah No 1 & Selatan & $\begin{array}{c}\text { Perisai } \\
\text { Ganda, } \\
\text { Bahan } \\
\text { genteng bata } \\
\text { merah }\end{array}$ & $\begin{array}{c}\text { Ayun } \\
\text { Tunggal, } \\
\text { Bahan Kayu } \\
\text { Jati dan Kaca }\end{array}$ & $\begin{array}{c}\text { Kupu } \\
\text { Tarung, } \\
\text { Bahan Kayu } \\
\text { Jati dan } \\
\text { Kaca }\end{array}$ & $\begin{array}{c}\text { Segi 4, } \\
\text { Bahan Bata } \\
\text { merah } \\
\text { diplester }\end{array}$ & $\begin{array}{c}\text { Ditinggi } \\
\text { kan }\end{array}$ \\
\hline 2. & Rumah $\mathrm{N}$ & Selatan & $\begin{array}{c}\text { Pelana } \\
\text { Bahan } \\
\text { genteng bata } \\
\text { merah }\end{array}$ & $\begin{array}{c}\text { Kupu } \\
\text { Tarung, } \\
\text { BahanKayu } \\
\text { Jati dan panil }\end{array}$ & $\begin{array}{c}\text { Kupu } \\
\text { Tarung, } \\
\text { Bahan Kayu } \\
\text { Jati dan } \\
\text { panil }\end{array}$ & $\begin{array}{c}\text { Segi 4, } \\
\text { Bahan Bata } \\
\text { merah } \\
\text { diplester }\end{array}$ & $\begin{array}{c}\text { Ditinggi } \\
\text { kan }\end{array}$ \\
\hline 3. & Rumah No 3 & Selatan & $\begin{array}{c}\text { Perisai } \\
\text { (kopel) } \\
\text { Bahan } \\
\text { genteng bata } \\
\text { merah }\end{array}$ & $\begin{array}{c}\text { Kupu } \\
\text { Tarung,Baha } \\
\text { n Kayu Jati } \\
\text { dan panil }\end{array}$ & $\begin{array}{c}\text { Kupu } \\
\text { Tarung,Bah } \\
\text { an Kayu Jati } \\
\text { dan panil }\end{array}$ & $\begin{array}{c}\text { Segi } 4 \text { dan } \\
\text { Bulat, } \\
\text { Bahan Bata } \\
\text { merah } \\
\text { diplester }\end{array}$ & $\begin{array}{c}\text { Ditinggi } \\
\text { kan }\end{array}$ \\
\hline 4. & Rumah No 4 & Selatan & $\begin{array}{c}\text { Perisai } \\
\text { Bahan } \\
\text { genteng bata } \\
\text { merah }\end{array}$ & $\begin{array}{c}\text { Kupu } \\
\text { Tarung,Baha } \\
\text { n Kayu Jati } \\
\text { dan panil }\end{array}$ & $\begin{array}{c}\text { Kupu } \\
\text { Tarung,Bah } \\
\text { an Kayu Jati } \\
\text { dan panil }\end{array}$ & $\begin{array}{c}\text { Segi 4, } \\
\text { Bahan Bata } \\
\text { merah } \\
\text { diplester }\end{array}$ & $\begin{array}{c}\text { Ditinggi } \\
\text { kan }\end{array}$ \\
\hline 5. & Rumah No 5 & Selatan & $\begin{array}{c}\text { Perisai } \\
\text { Bahan } \\
\text { genteng bata } \\
\text { merah }\end{array}$ & $\begin{array}{c}\text { Kupu } \\
\text { Tarung,Baha } \\
\text { n Kayu Jati, } \\
\text { panil dan } \\
\text { kaca }\end{array}$ & $\begin{array}{c}\text { Kupu } \\
\text { Tarung,Bah } \\
\text { an Kayu Jati, } \\
\text { panil dan } \\
\text { kaca }\end{array}$ & $\begin{array}{c}\text { Segi 4, } \\
\text { Bahan Bata } \\
\text { merah } \\
\text { diplester }\end{array}$ & $\begin{array}{c}\text { Ditinggi } \\
\text { kan }\end{array}$ \\
\hline 6. & 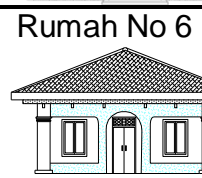 & Selatan & $\begin{array}{c}\text { Perisai } \\
\text { Bahan } \\
\text { genteng bata } \\
\text { merah }\end{array}$ & $\begin{array}{c}\text { Kupu } \\
\text { Tarung,Baha } \\
\text { n Kayu Jati } \\
\text { dan panil }\end{array}$ & $\begin{array}{c}\text { Kupu } \\
\text { Tarung,Bah } \\
\text { an Kayu Jati } \\
\text { dan panil }\end{array}$ & $\begin{array}{c}\text { Segi 4, } \\
\text { Bahan Bata } \\
\text { merah } \\
\text { diplester }\end{array}$ & $\begin{array}{c}\text { Ditinggik } \\
\text { an }\end{array}$ \\
\hline 7. & & Selatan & $\begin{array}{c}\text { Perisai } \\
\text { Bahan } \\
\text { genteng bata } \\
\text { merah }\end{array}$ & $\begin{array}{c}\text { Kupu } \\
\text { Tarung, } \\
\text { Bahan Kayu } \\
\text { Jati,panil dan } \\
\text { kaca }\end{array}$ & $\begin{array}{c}\text { Kupu } \\
\text { Tarung, } \\
\text { Bahan Kayu } \\
\text { Jati, panil } \\
\text { dan kaca }\end{array}$ & $\begin{array}{c}\text { Segi } 4 \text { dan } \\
\text { Bulat, } \\
\text { Bahan Bata } \\
\text { merah } \\
\text { diplester }\end{array}$ & $\begin{array}{c}\text { Ditinggi } \\
\text { kan }\end{array}$ \\
\hline 8. & & Utara & $\begin{array}{c}\text { Perisai } \\
\text { Bahan } \\
\text { genteng bata } \\
\text { merah }\end{array}$ & $\begin{array}{c}\text { Ayun } \\
\text { Tunggal, } \\
\text { Kayu Jati, } \\
\text { panil dan } \\
\text { kaca }\end{array}$ & $\begin{array}{c}\text { Kupu } \\
\text { Tarung, } \\
\text { Kayu Jati, } \\
\text { panil dan } \\
\text { kaca }\end{array}$ & Tidak ada & $\begin{array}{c}\text { Ditinggi } \\
\text { kan }\end{array}$ \\
\hline 9. & Rumah No 9 & Utara & $\begin{array}{c}\text { Pelana } \\
\text { Bahan } \\
\text { genteng bata } \\
\text { merah }\end{array}$ & $\begin{array}{c}\text { Kupu } \\
\text { Tarung, } \\
\text { Kayu Jati, } \\
\text { panil dan } \\
\text { kaca }\end{array}$ & $\begin{array}{c}\text { Kupu } \\
\text { Tarung, } \\
\text { Kayu Jati, } \\
\text { panil dan } \\
\text { kaca }\end{array}$ & $\begin{array}{c}\text { Segi } 4 \text { dan } \\
\text { Bulat, } \\
\text { Bahan Bata } \\
\text { merah } \\
\text { diplester }\end{array}$ & $\begin{array}{c}\text { Ditinggi } \\
\text { kan }\end{array}$ \\
\hline 10. & Rumah No 10 & Utara & $\begin{array}{c}\text { Pelana } \\
\text { Bahan } \\
\text { genteng bata } \\
\text { merah }\end{array}$ & $\begin{array}{c}\text { Kupu } \\
\text { Tarung, } \\
\text { Kayu Jati, } \\
\text { panil dan } \\
\text { kaca }\end{array}$ & $\begin{array}{c}\text { Kupu } \\
\text { Tarung, } \\
\text { Kayu Jati, } \\
\text { panil dan } \\
\text { kaca }\end{array}$ & $\begin{array}{c}\text { Segi } 4 \text { dan } \\
\text { Bulat, } \\
\text { Bahan Bata } \\
\text { merah } \\
\text { diplester }\end{array}$ & $\begin{array}{c}\text { Ditinggi } \\
\text { kan }\end{array}$ \\
\hline 11. & \begin{tabular}{|c|} 
Rumah No 11 \\
用 \\
雨 \\
\end{tabular} & Timur & $\begin{array}{c}\text { Perisai } \\
\text { Bahan } \\
\text { genteng bata } \\
\text { merah }\end{array}$ & $\begin{array}{c}\text { Kupu } \\
\text { Tarung, } \\
\text { Kayu Jati, } \\
\text { panil dan } \\
\text { kaca }\end{array}$ & $\begin{array}{c}\text { Kupu } \\
\text { Tarung, } \\
\text { Kayu Jati, } \\
\text { panil dan } \\
\text { kaca }\end{array}$ & Tidak ada & $\begin{array}{c}\text { Ditinggi } \\
\text { kan }\end{array}$ \\
\hline
\end{tabular}


Lanjutan Tabel I. Matriks Tipologi Wajah Bangunan 16 Bangunan Objek Penelitian

\begin{tabular}{|c|c|c|c|c|c|c|c|}
\hline NO & $\begin{array}{l}\text { NOMOR } \\
\text { RUMAH }\end{array}$ & $\begin{array}{l}\text { ORIENTASI } \\
\text { WAJAH } \\
\text { BANGUNAN }\end{array}$ & TIPE ATAP & $\begin{array}{c}\text { TIPE } \\
\text { JENDELA }\end{array}$ & TIPE PINTU & $\begin{array}{c}\text { TIPE } \\
\text { KOLOM }\end{array}$ & $\begin{array}{c}\text { TIPE } \\
\text { LANTAI }\end{array}$ \\
\hline 12. & $\begin{array}{ll}\text { Rumah No } 12 \\
\square \square\end{array}$ & Barat & $\begin{array}{c}\text { Pelana, } \\
\text { Bahan } \\
\text { genteng } \\
\text { bata merah }\end{array}$ & $\begin{array}{c}\text { Tidak ada, } \\
\text { Bahan Kayu } \\
\text { jati, panil }\end{array}$ & $\begin{array}{c}\text { Kupu } \\
\text { Tarung dan } \\
\text { Geser, } \\
\text { Bahan Kayu } \\
\text { jati, panil }\end{array}$ & Tidak ada & $\begin{array}{c}\text { Ditinggi } \\
\text { kan }\end{array}$ \\
\hline 13. & Rumah No 13 & Selatan & $\begin{array}{c}\text { Perisai, } \\
\text { Bahan } \\
\text { genteng } \\
\text { bata merah }\end{array}$ & $\begin{array}{c}\text { Kupu } \\
\text { Tarung, } \\
\text { Bahan Kayu } \\
\text { jati, panil, } \\
\text { jalusi }\end{array}$ & $\begin{array}{c}\text { Kupu } \\
\text { Tarung, } \\
\text { Bahan Kayu } \\
\text { jati, panil, } \\
\text { jalusi }\end{array}$ & Tidak ada & $\begin{array}{c}\text { Ditinggi } \\
\text { kan }\end{array}$ \\
\hline 14. & 我四四 & Selatan & $\begin{array}{c}\text { Perisai, } \\
\text { Bahan } \\
\text { genteng } \\
\text { bata merah }\end{array}$ & $\begin{array}{c}\text { Kupu } \\
\text { Tarung, } \\
\text { Bahan Kayu } \\
\text { Jati, panil } \\
\text { dan kaca }\end{array}$ & $\begin{array}{c}\text { Kupu } \\
\text { Tarung, } \\
\text { Bahan Kayu } \\
\text { Jati, panil } \\
\text { dan kaca }\end{array}$ & $\begin{array}{c}\text { Segi 4, } \\
\text { Bahan Bata } \\
\text { merah } \\
\text { diplester }\end{array}$ & $\begin{array}{c}\text { Ditinggi } \\
\text { kan }\end{array}$ \\
\hline 15. & Rumah No 15 & Selatan & $\begin{array}{c}\text { Pelana, } \\
\text { Bahan } \\
\text { genteng } \\
\text { bata merah }\end{array}$ & $\begin{array}{c}\text { Kupu } \\
\text { Tarung, } \\
\text { Bahan Kayu } \\
\text { Jati, panil } \\
\text { dan kaca }\end{array}$ & $\begin{array}{c}\text { Kupu } \\
\text { Tarung, } \\
\text { Bahan Kayu } \\
\text { Jati, panil } \\
\text { dan kaca }\end{array}$ & $\begin{array}{c}\text { Segi 4, } \\
\text { Bahan Bata } \\
\text { merah } \\
\text { diplester }\end{array}$ & $\begin{array}{c}\text { Ditinggi } \\
\text { kan }\end{array}$ \\
\hline 16. & 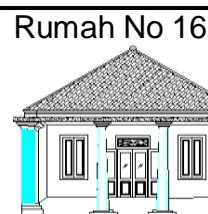 & Selatan & $\begin{array}{c}\text { Perisai, } \\
\text { Bahan } \\
\text { genteng } \\
\text { bata merah }\end{array}$ & $\begin{array}{c}\text { Kupu } \\
\text { Tarung. } \\
\text { Bahan Kayu } \\
\text { Jati, panil }\end{array}$ & $\begin{array}{c}\text { Kupu } \\
\text { Tarung, } \\
\text { Bahan Kayu } \\
\text { Jati, panil }\end{array}$ & $\begin{array}{c}\text { Segi } 4 \text { dan } \\
\text { segi 8, } \\
\text { Bahan Bata } \\
\text { merah } \\
\text { diplester }\end{array}$ & $\begin{array}{c}\text { Ditinggi } \\
\text { kan }\end{array}$ \\
\hline
\end{tabular}

Sumber: Hasil Penelitian, 2014

Selain terkait bentuk elemen bangunan, orientasi wajah bangunan juga memiliki makna bagi masyarakat jawa, secara umum arah bangunan bergaya kolonial yang ada di kota Krian mengarah ke utara dan selatan. Hal ini ternyata menyesuaikan dengan arah yang merupakan simbolisasi arah yang baik.

Arah selatan adalah arah yang umumnya digunakan oleh masyarakat jawa karena berkaitan dengan tempat tinggal penguasa laut selatan Anataboga (Nyai Roro Kidul) yang membawa keselamatan dan kesuksesan, sedangkan arah utara adalah arah yang umumnya digunakan oleh masyarakat jawa karena berkaitan dengan dewa wisnu sebagai dewa pelindung. Dengan orientasi ke arah utama maka diharapkan kehidupan pemilik rumah akan selalu aman dalam menjalani kehidupan di dunia (Frick, 2010).

Terkait ornamen hias, bangunanbangunan bergaya kolonial di Kota Krian sangat minim penggunaan ornamen hias.Hal ini dikarenakan keterbatasan kemampuan tukangtukang lokal pada masa itu dalam membuat ornamen pada media beton.Para tukang-tukang lokal tersebut umumnya hanya mahir dalam membuat ornamen pada media kayu dan bambu.Oleh sebab itu, ornamen hias pada umum ditemukan pada bouvenlinch, dan tidak semuanya memiliki makna sebab hanya sebagai penghias saja. Ornamen hias pada bouvenlinchyang memiliki makna hanya pada bentuk busur panah yang 
merupakan simbolisasi dari rasa aman (supaya penghuni aman).

Dengan demikian, elemen-elemen wajah bangunan pada bangunan kolonial di kota Krian ternyata memiliki makna lokalitas yang masih dijaga sampai saat ini. Penerapan simbolisasi bentuk elemen wajah bangunan pada bangunan bergaya kolonial di Kota Krian oleh masyarakat lokal mungkin tidak semua orang mampu memahami makna yang ingin disampaikan. Intinya, walaupun bangunan buka bergaya arsitektur jawa tetapi secara bentuk dan simbol masih tetap dapat dituangkan tradisi dan kepercayaan yang ada dalam masyarakat jawa.

\section{Kesimpulan dan Saran \\ 4.1 Kesimpulan}

Padahakekatnya, rumahmerupakan cerminkehidupanyangmenggambarkanj atidiriorangJawa dan ditampilkandalamwujudbangunan terutama wajah bangunan, untuk menyampaikan

kehidupannya,sosialnya,spiritualdanbu dayanya.

Dari makna bentuk elemen wajah bangunan bahwa walaupun wujud bangunan adalah gaya kolonial belanda karena memang pada masa itu sedang menjadi tren, tetapi bangunan belanda tersebut sebagai wujud untuk menyampaikan bahwa secara ekonomi bahwa pemilik rumah adalah orang berada atau orang kaya karena bangunan bergaya kolonial memerlukan material dan biaya yang tidak sedikit.

Paradigma orang jawa bahwa dalam hidup harus selaras dengan Tuhan, selaras dengan alam dan selaras dengan sosial diwujudkan dalam simbolisasi pada bentuk elemen wajah bangunan kolonial di kota Krian. Dari bentuk atap yang merupakan simbolisasi gunung yang sejalan dengan paradigma selaras dengan Tuhan, pintu dan jendela yang berbentuk kupu tarung yang merupakan wujud selaras dengan sosial yang terbuka (antara batinial dan lahariah jadi satu) sehingga rezeki dan kebahagiaan akan datang. Selain itu bentuk kolom juga memberikan simbolisasi kesempurnaan Tuhan dan ketidaksempurnaan manusia dalam hidup.Bahkan pada konsep peninggian lantai, tidak hanya sebagai bentuk adaptasi terhadap lingkungan yang sering tergenang, tetapi juga memantapkan bahwa rumah itu memiliki nilai sakral.Kesemuanya itu disempurnakan dengan orientasi wajah bangunan pada arah utara dan selatan yang memang bermakna baik terkait utara merupakan simbolisasi dewa wisnu sebagai pelindung dan selatan adalah nyi roro kidul sebagai simbolisasi rezeki dan keselamatan.

Lokalitas makna tersebut tentu merupakan kekayaan budaya masyarakat kota Krian yang perlu dipahami.

\subsection{Saran}

Penelitian ini terbatas lebih pada masalah fisik deskriptif (ditinjau dari segi arsitektur lingkungan dan bangunan khususnya) tentang salah satu elemen arsitektur yakni wajah bangunan kolonial sebagai fokus penelitian. Perlu penelitian bekelanjutan yang bersifat lebih detil dan spesifik misal pada skala masing-masing unit bangunan mengenai perkembangan tatanan ruang luar dan ruang dalam dapat berupa pergeseran -pergeseran fisik tatanan ruang dalam konstruksi dan sebagainya atau mengenai elemen lingkungan (lay out plan, pencitraan visual kawasan)

Bagi pemerintah, sangat perlu untuk melakukan kajian bangunanbangunan kuno terutama kolonial di kota Krian karena bangunan-bangunan tersebut adalah kekayaan budaya dan arsitektur nusantara yang perlu mendapat perhatian baik dari sisi pelestarian dan preservasi. 


\section{Daftar Pustaka}

Dakung, Sugiyarto. 1981. Arsitektur Tradisional Daerah Istimewa Yogyakarta. Departemen Pendidikan dan Kebudayaan, Yogyakarta

Dewi, N.K.A. 2003.Geomerti, Simetri dan Religiusitas pada Rumah Tinggal Tradisional di Indonesia. Jurnal Permukiman Natah I (1); 2942

Fauzi, B. 2011.Memahami Relasi Fungsi, Bentuk dan makna Arsitektur Rumah Tinggal Masyarakat Kota Pesisir Utara di Kawasan Jawa Timur. Jurnal DIMENSI, XXXVIII (2); 79-88

Frick, H. 1997. Pola Struktur dan Teknik Bangunan di Indonesia. Penerbit Kanisius, Yogyakarta

Frick, H. 2010. Pola Struktur dan Teknik Bangunan di Indonesia. Penerbit Kanisius, Yogyakarta

Ismunandar. 1986. Joglo: Arsitektur Rumah Tradisional Jawa. Penerbit Dahara Prize, Semarang,

Krier, R. 1988. Architectural Composition. Academy Edition, London

Krier, R. 2001. Komposisi Arsitektur, Erlangga, Jakarta

Lippsmeier, G. 1980. Bangunan Tropis (Edisi ke-2). Erlangga, Jakarta

Noeradya, Siti Woeryan Soemadiyah. (2005). Attassadhur Adammakna. CV. Buana Raya, Yogyakarta

Philips, D dan Gardner, C. 2004.Daylighting - Natural Light in Architecture. Architectural Press, Oxford
Rossi, Aldo. 1982. Architecture of the City. The MIT Press, LondonEngland

Satwiko, P. 2013. Aspek Energi pada Arsitektur Nusantara. SAN 2 Arsitektur Nusantara Berkelanjutan; 1-13, Malang, Jurusan Arsitektur Fakultas Teknik Universitas Brawijaya 